\title{
Elucidação comparativa dos estudos em psicanálise e educação na França e no Brasil: a psicanálise aplica-se à educação?
}

\section{Comparative clarification between studies on psychoanalysis and education in France and in Brazil: is psychoanalysis applied to education?}

\author{
Leandro de Lajonquière ${ }^{1}$
}

\begin{abstract}
RESUMO
A partir dos elementos aportados por dois recenseamentos franceses e dois brasileiros sobre os desenvolvimentos em psicanálise e educação, realizados por grupos consagrados de pesquisadores, este texto pretende elucidar comparativamente os avanços em cada país, bem como assinalar as limitações inerentes à proposta de se aplicar a psicanálise à educação.

Palavras-chave: psicanálise e educação; aplicação da psicanálise; Freud; Maud Mannoni.
\end{abstract}

\begin{abstract}
With the contributions of the data arisen from two studies in France and two studies in Brazil developed in the field of psychoanalysis and education, carried out by renowned research teams, this text intends to elucidate, in a comparative way, the advances of this subject in each country. It also intends to underline intrinsic limitations of psychoanalysis application to education.

Keywords: psychoanalysis and education; psychoanalysis application; Freud; Maud Mannoni.
\end{abstract}

DOI: $10.1590 / 0104-4060.49813$

1 Université Paris 8 Vincennes Saint-Denis. Unité de Formation et Recherche. Sciences de l'éducation, Psychanalyse et Français Langue étrangère. Saint Denis, França. 2 Rue de la Liberté. CEP: 93000.E-mail:1delajon@usp.br 
A circulação e o desenvolvimento das ideias no decorrer dos tempos não obedecem a uma lógica linear e mecânica. Isso não é novidade, porém, esse sonho insiste em todos nós até quando dos destinos da psicanálise se trata. Assim, é bom lembrarmos que os desdobramentos da psicanálise inventada por Sigmund Freud descrevem há mais de um século circuitos inusitados. Não sei se esses são mais inusitados que aqueles dos outros campos, porém, certamente a psicanálise comparte com os saberes sociais e as humanidades o fato de suas implantações e desenvolvimentos estarem sujeitos às idiossincrasias existenciais da vida local. Ao contrário, os postulados e axiomas das matemáticas têm sempre o mesmo valor, seja na Coreia do Norte, na França, no Brasil ou na nossa vizinha Argentina.

Freud conhecia, falava e/ou lia outras línguas além da alemã, mas foi no interior da língua de Goethe que a psicanálise foi inventada, sendo a língua materna dos primeiros pacientes, de seus primeiros colegas Josef Breuer e Wilhem Flies, bem como de seus primeiros discípulos. Com o tempo, o avanço do nazismo e a Segunda Guerra, a psicanálise acabou por fincar pé na Inglaterra e nos USA. $O$ fato de a psicanálise ser praticada tanto em inglês quanto em outras latitudes imprimiu torções singulares no seu desdobramento teórico-clinico. Por exemplo, foi escutando os pacientes norte-americanos que os analistas chegados da Europa concluíram que o norte de uma análise deveria ser o reforçamento da suposta autonomia do Ego. Depois foi a vez da língua francesa. A psicanálise demorou "para pegar" na França - conforme nossa expressão bem brasileira. Porém, quando assim foi, ela experimentou outra reviravolta sob o mote de retornarmos a Freud no dizer de Jacques Lacan. Porém, há certo tempo que a psicanálise se consolidou de vez no Brasil e na Argentina ao ponto tal que nossos medos, esperanças e sonhos tecidos no português do Brasil e no espanhol do Rio da Plata passaram a produzir efeitos no campo dos estudos e debates psicanalíticos.

Quando a psicanálise chegou ao Brasil, Freud ainda estava vivo e morava em Viena. Devemos a empreitada a médicos como Durval Marcondes, Arthur Ramos e Deodato de Moraes. Mais ainda, assim como repetindo o gesto acontecido nos primórdios austro-húngaros, a psicanálise, logo após ter fincado pé aqui, interessou-se nas crianças e, portanto, na sua educação tanto familiar quanto escolar. Elisabete Mokerjs (1992) lembra, dentre outros detalhes da saga da implantação da psicanálise no Brasil, que ela se fez presente em diversas seções de Higiene Mental Escolar, bem como que, em 1934, viria à luz o livro de Arthur Ramos intitulado Psicanálise e Educação. Assim sendo, Arthur Ramos deveria ser considerado o nosso Oskar Pfister tropical. Foi de fato esse último pastor e pedagogo - quem publicou, em 1913, em Leipzig, o primeiro livro de psicanálise, destinado a leitores pedagogos - Die psychoanalytische Methode. 
O título do livro de Arthur Ramos acabou com o tempo virando um sintagma guarda-chuva que possibilita hoje em dia a numerosos praticantes da psicanálise, docentes e pesquisadores universitários, particularmente nas áreas de psicologia e de educação, nomear a forma que eles têm de trabalhar e de fazer trabalhar ou operar a psicanálise quando se trata da educação das crianças. No entanto, entre a época de Ramos e os dias de hoje, a psicanálise não é mais a mesma nem no Brasil nem alhures. Foge a este texto historiar semelhanças e diferenças espalhadas pelo planeta. O que me interessa nesta oportunidade é circunscrever, mesmo aproximativamente, o perímetro epistemológico desse conjunto de estudos que o sintagma psicanálise e educação recobre hoje em dia no Brasil.

Como afirmei recentemente num evento cientifico ${ }^{2}$ que congregou universitários praticantes da psicanálise implicados de uma ou outra forma com a educação, o nosso trabalho carrega em seu bojo as marcas de nossa própria relação à psicanálise e seus desdobramentos, as das particularidades de nossa vida cotidiana com as crianças e a história e o presente da escolarização em nosso país. Até certo ponto dizer isto é uma obviedade, mas não poucas vezes ela passa despercebida. Em quase todas as latitudes onde a psicanálise se faz presente, há trabalhos em psicanálise e educação. No entanto, o que por isso se entende, o que é estudado e discutido, as formas de se operar com a psicanálise, não se equivalem, embora possa haver maiores ou menores ressonâncias devido aos laços transferenciais entre os interessados e devido aos ecos das histórias nacionais ${ }^{3}$.

Para Sigmund Freud, a psicanálise era uma criatura especial. Para além de ele reconhecer que a sua invenção era a sua criatura - com tudo o que essa afirmação pode fazer ressoar nos nossos ouvidos luso-castelhanos - ela era singular, pois não é uma, mas três, onde cada dimensão implica necessariamente as outras duas, de forma tal que se uma delas vier a se soltar, então, a psicanálise acaba desaparecendo. (FREUD, 1923). Freud inventou de uma tacada só uma terapêutica para o sofrimento existencial, uma técnica de investigação, bem como uma rede de noções, conceitos e formas de operar com eles batizada de metapsicologia.

2 Trata-se do XI Colóquio internacional do LEPSI, que teve lugar na UFMG, em Belo Horizonte, nos dias 21, 22 e 23 de setembro de 2016, reunindo mais de 300 participantes e 200 comunicações. O Laboratório de Estudos e Pesquisas Educacionais sobre a Infância, fundado em 1998 na Universidade de São Paulo pelos professores Maria Cristina M. Kupfer e Leandro de Lajonquière, associa atualmente docentes e/ou pesquisadores, bem como alunos de graduação e pós-graduação da USP, da UNIFESP/Guarulhos, da UFOP e da UFMG.

3 Assim como o nazismo esteve em causa na primeira diáspora de analistas europeus para as Américas, outros totalitarismos políticos vieram a pautar outros êxodos massivos de psicanalistas como, por exemplo, a última ditadura militar argentina. 
Nenhuma dessas dimensões pode ser entendida fora do conjunto. Talvez seja essa a pedra no sapato daqueles que pretendem dela se aproximar. Costuma-se dizer que para adentrarmos na psicanálise devemos tentar fazer ao menos uma análise na vida. Essa afirmação não invalida minha afirmação precedente. Elas são solidárias. Então, talvez devamos ter claro que a experiência singular de uma análise é peça-chave no entendimento dessa intrínseca singularidade que há entre as três dimensões: a terapêutica, a técnica e a metapsicológica.

Hoje é consenso entre os praticantes da psicanálise que essa tripla dimensão faz com que a psicanálise seja o que ela é, e não outra coisa. Isso faz com que os analistas reconheçam que Sigmund Freud foi, é e sempre será o pai dessa singular criatura. E, claro que, quando do pai se trata, os filhos medem diferença à sua maneira. Isso, até certo ponto, faz, precisamente, diferença entre as diversas escolas e correntes. Já quem não reconhece a existência da criatura e que o pai dessa foi e é Sigmund Freud, cai automaticamente fora da família. A lista dos autoexcluídos logo foi aberta nos primórdios da psicanálise por Alfred Adler e Carl Jung.

No entanto, o panorama dos trabalhos em psicanálise e educação constitui um capítulo à parte desta novela familiar. Neste caso, acontece algo curioso. $\mathrm{Na}$ extremidade da gama de matizes bem encontramos trabalhos que, ignorando de forma mais ou menos deliberada Freud e a sua criatura, reivindicam de diversos modos o uso do termo psicanálise. É o caso, por exemplo, de alguns trabalhos na França. Elucidar as razões desse fenômeno foge também aos limites deste ensaio. Porém, tentaremos esboçar um contraste entre os desenvolvimentos psicanalíticos na educação no Brasil e, por outro lado, os franceses, que configuram um campo, até certo ponto díspar na forma de convocar a psicanálise, batizado Abordagem clínica de orientação psicanalítica em ciências da educação. Assim, esperamos contribuir com a elucidação da qualidade daquilo que atualmente fazemos no Brasil sob o tão genérico mote de psicanálise e educação, proposto há quase um século por Arthur Ramos.

\section{A pluralidade da psicanálise}

Na França há duas publicações que sintetizam e ordenam até certo ponto as reflexões e experiências que vieram à luz no campo educativo e pedagógico a partir de uma referência à psicanálise na sua pluralidade. A primeira é o artigo de Jean-Claude Filloux intitulado Psychanalyse et pédagogie: ou d'une prise en compte de l'inconscient dans le champs pedagogique (1987). A segunda é Re- 
cherches cliniques d'orientation psychanalytique dans le champ de l'éducation et de la formation (2005) de autoria conjunta de Claudine Blanchard-Laville, Philippe Chaussecourte, Françoise Hatchuel e Bernard Pechberty. A primeira publicação tenta ordenar sumariamente as produções até a década de oitenta considerando como pontapé inicial dessa história a iniciativa editorial empreendida, entre os anos 1926 e 1938, pelo psicanalista Heinrch Meng e pelo psicopedagogo Ernst Schneider: Zetschrift für Psychoanalytische Pädagogik4 . Já a segunda publicação tenta elaborar outros critérios de ordenamento, bem como, mais densa e documentada, constitui uma radiografia preciosa da diversidade que caracteriza esse campo de estudos e pesquisa.

No Brasil, na esteira dessas duas iniciativas dos colegas franceses, Maria Cristina Kupfer e Marcelo Ricardo Pereira coordenaram em duas oportunidades trabalhos de recenseamento e análise da produção brasileira. Os resultados foram apresentados em A produção brasileira no campo das articulações entre psicanálise e educação a partir de 1980 (KUPFER, 2010) e Análise do estado da arte em psicanálise e educação (1987-2012). (PEREIRA, 2015).

Entre os desenvolvimentos de ambos os países parece haver uma coincidência no que tange à época de consolidação dos estudos em psicanálise e educação - as últimas três décadas do século XX na França, bem como as últimas duas no Brasil. No entanto, é sabido que, logo que a psicanálise foi instalada nas primeiras décadas do século passado em ambos os países, foi se consolidando aos poucos uma prática clínica com crianças levadas à consulta pelos mais diversos motivos, dentre os quais os ditos problemas na aprendizagem escolar. Entretanto, essa prática não chega a ser considerada pelos recenseadores de ambos os lados do Atlântico como integrando o campo de estudos em psicanálise e educação: ela permanece dentro das fronteiras psicanalíticas consagradas, embora não sem pouca discussão durante anos no que tangia a especificidade e a legitimidade em si de uma "psicanálise com crianças".

Assim sendo, para que uma iniciativa possa ser considerada psicanalítica no campo da educação, parece que ela deve apresentar algo a mais que o simples interesse de receber na consulta psicanalítica crianças às voltas com a experiência escolar. Porém, a consolidação dessa clínica foi peça-chave na entrada da psicanálise no campo educativo. Parece que, após algumas décadas escutando crianças, os adultos passaram a interrogar a experiência escolar em si mesma, as instituições pedagógicas, as organizações educativas, os votos e anseios pedagógicos adultos, a educação familiar, o exercício do magistério; em suma, passaram a questionar a mesmíssima acolhida que o próprio mundo adulto

4 A revista editada primeiro em Stutgart foi pouco tempo depois, devido a dificuldades financeiras, relançada em Viena com o nome Verlag der psychoanlytische Pädagogik. 
reserva às crianças na vida cotidiana. Em certo sentido, isso não era nenhuma novidade, pois o próprio Freud já tinha assinalado essa necessidade quando afirmou que a educação da época encaminhava as crianças numa excursão ao polo norte, vestidas com as roupas de verão e munidas com os mapas dos lagos italianos. (FREUD, 1930).

Um primeiro contraste entre as publicações francesas e as brasileiras já dá uma ideia do caráter singular dos desenvolvimentos em cada país.

Enquanto no Brasil há uma dispersão temática (infância, adolescência, mal-estar docente, violência, educação terapêutica, subjetividade contemporânea, inclusão escolar, etc.), na França constata-se certa concentração das pesquisas em torno daquilo que os colegas chamam "a relação com o saber" [le(s) rapport $a u(x)$ savoir(s)] e as dinâmicas grupais e institucionais. Mais ainda, ambas as temáticas confluem naquilo que é chamado "análise das práticas profissionais" [analise des pratiques professionnelles] e que constitui a forma hegemônica sob a qual a psicanálise se faz presente hoje na França no campo da educação e da formação. Ao contrário, no Brasil, a noção "relação com o saber" ocupa um lugar periférico nos estudos psicanalíticos. Já o trabalho em grupos se faz presente de diferentes formas, ora como dinâmica de intervenção junto às crianças em contextos diversos, ora como dispositivo de formação profissional continuada em particular junto aos docentes que, por exemplo, participam de experiências de inclusão escolar. Nos anos sessenta e setenta houve na França um marcado interesse pela questão institucional e a dinâmica de grupos, tanto no interior do campo psicanalítico, quanto nos campos sociológico, pedagógico e psicológico. De certa forma, esses desenvolvimentos conceituais, novos na época, ainda se fazem presentes na linha atual de pesquisa-ação dita "grupo de análise das práticas profissionais", que usufrui de certa hegemonia. Por outro lado, a noção "relação com o saber" não é de uso privativo dos pesquisadores franceses que se referem à psicanálise no campo da educação e da formação. Ela é também central na tradição de pesquisa sociológica inaugurada dentre outros por Bernard Charlot no início da década de noventa ${ }^{5}$. Isso é digno de nota, pois creio que o fato de ambas as tradições compartirem essa noção não é sem consequências no que tange à forma de os franceses se referirem à psicanálise no campo educativo e pedagógico. Mais ainda, o sintagma a "relação com o saber" tem se convertido ainda numa noção ostensivamente presente ao ponto tal de ter sido recuperada pelos documentos oficiais.

5 Cabe notar que, enquanto os sociólogos da educação na esteira das investigações de Charlot interrogam "a relação com o saber" de crianças e jovens, os pesquisadores que se valem da psicanálise focam, ao contrário, os profissionais e particularmente os docentes. 
A centralidade que "a relação com o saber" ocupa na reflexão dos pesquisadores franceses inspirados pela psicanálise obedece ainda a outra razão, qual seja, a referência à corrente anglo-saxônica de psicanálise (M. Klein, W. Bion, M. Balint, E. Bick e D. Winnicott). Trata-se de um fato singular, pois o cenário psicanalítico francês não é mais dominado pela corrente inglesa. Embora ele seja hoje marcado pela pluralidade, podemos constatar hoje a presença ostensiva de uma leitura diversificada dos textos lacanianos bem como desenvolvimentos originais por parte tanto de contemporâneos próximos a Lacan quanto de desafetuosos à sua obra e à sua personalidade.

No entanto, na França os pesquisadores no campo da educação e da formação inspirados pela leitura lacaniana constituem uma minoria. Durante alguns anos as suas reflexões se deram na esteira da corrente grupalista e institucionalista dos anos setenta ${ }^{6}$. Já o conhecido pioneirismo de Maud Mannoni situa-se num cruzamento de interrogações várias, o que faz justamente a sua singular riqueza: a renovação da clínica psicanalítica com crianças no intuito de incluir no seu interior as crianças psicóticas e autistas, o questionamento da institucionalização da psicanálise, bem como do imaginário pedagógico hegemônico. A iniciativa de Mannoni, longe de ser um fato isolado, teve lugar numa época na qual a psicanálise passou a se fazer de fato presente de diferentes formas no vasto e diverso panorama institucional de atenção psicossocial e educativa financiado pelo sistema de seguridade social francês. No entanto, o trabalho de reflexão causado por essa presença diversa da psicanálise fora dos muros dos consultórios particulares nunca reivindicou para si o mote de "psicanálise e educação", na França. A exceção a essa regra vem novamente de Maud Mannoni e sua equipe, que ousaram, embora produzindo certo deslocamento, aproximar ambos os termos, batizando a associação gestora da Ecole de Bonneuil, em 1969, de Centre d'études et de recherches psychanalytiques et pédagogiques ${ }^{7}$.

Já no que tange ao Brasil a situação é quase que inversa, pois a grande maioria - mas não absoluta - dos estudos psicanalíticos na educação responde, mesmo que de forma distante, por uma inspiração lacaniana. Mais ainda, a consolidação dos mesmos está até certo ponto atrelada aos destinos do ensino mannoniano, transmitido graças ao retorno de numerosos estagiários brasileiros em Bonneuil $^{8}$. Nesse contexto, então, compreende-se que tanto brasileiros quanto franceses mais ou menos leitores de Lacan não façam do sintagma "a relação com o saber" o leitmotiv da pesquisa psicanalítica em educação e formação.

6 Dentre outros, cabe citar Francis Imbert e Jacques Pain.

7 Quando da criação do LEPSI e no intuito de tomar distância da matriz tecno-cientificista da pedagogia, os fundadores retomaram na apelação o termo "educação" em lugar de "pedagogia".

8 Kupfer e Lajonquière realizaram estágio na Ecole de Bonneuil no início dos anos 1990. 
Para esses, a questão não passa pela relação ao saber, porém pela referência à castração e ao desejo.

Outro elemento que salta à vista contrastando as publicações que retratam o estado da arte é a insistência na França de questões tais como a especificidade e a legitimidade própria aos estudos psicanalíticos para além das estritas fronteiras da prática da cura. O texto da equipe coordenada por Blanchard-Laville apresenta como sendo métodos de pesquisa: a observação, a entrevista e a dinâmica grupal. Esses dispositivos são considerados clínicos e, portanto, legítimos se obedecerem a certas regras padronizadas a partir de noções psicanalíticas sobre a dinâmica da transferência-contratransferência. Ao contrário, no Brasil não nos vemos com a urgência de justificar permanentemente por que recorremos à psicanálise na educação, e também não nos sentimos obrigados a elucidar a especificidade metodológica de cada abordagem. Nesse sentido, ao contrário da França, os trabalhos brasileiros que contemplam o dinamismo grupal como pesquisa-ação constituem uma minoria. Por outro lado, sob a observação recai certa desconfiança generalizada, enquanto as entrevistas quando realizadas não respondem ao espírito psicológico clínico próprio aos anos 1960 e 1970 tomado no contraponto transferência/contratransferência. (BLEGER, 1964). Finalmente, no Brasil a intervenção psicanalítica junto às crianças, seus pais, seus professores ou educadores em diferentes contextos aparece como sendo a modalidade por excelência da pesquisa no nosso campo, junto à leitura na vida cotidiana do que consideramos sendo "sintomas sociais". Isso obedeceria a uma série de razões.

Por um lado, a quase totalidade dos pesquisadores franceses está institucionalmente inserida no âmbito universitário de ciências da educação e tão somente uma minoria reivindica praticar a psicanálise. Mas, ainda quando a reivindica, o colega francês faz questão de distinguir entre a psicanálise e aquilo que hoje é conhecido na França como a "Abordagem clínica de inspiração psicanalítica no campo das ciências da educação". No Brasil, os interessados na psicanálise e educação situam-se em partes iguais nos âmbitos da educação e da psicologia universitárias. Mais ainda, embora na educação ou na pedagogia, uma boa porcentagem dos pesquisadores universitários se diz praticante da psicanálise, seja porque realiza tão somente uma análise pessoal, seja porque acabou virando analista. Finalmente, no Brasil recorre-se a diferentes fórmulas como, por exemplo, "aproximações entre a psicanálise e educação", "o casamento da psicanálise com a educação", a "conexão psicanálise e educação" ou, a minha última proposição, "a psicanálise na educação" (LAJONQUIÈRE, 2009), porém, nenhuma delas faz da psicanálise um adjetivo, nem evoca expressamente a finalidade de ela se inserir no contexto das "ciências" da educação. Em suma, enquanto a grande maioria dos brasileiros é de psicanalistas interessados na educação, a dos franceses é de formados no interior do vasto campo das ciências 
da educação que recorrem à psicanálise como matriz de leitura hermenêutica ou fonte de inspiração para montar dispositivos grupais de acompanhamento do exercício profissional. E isso faz toda a diferença entre os desenvolvimentos de ambos os países.

Que uns - os franceses - sejam apegados ao esclarecimento metodológico com vistas a reivindicar a legitimidade da pesquisa, enquanto que os outros apresentam maior tranquilidade no que tange à natureza psicanalítica da investigação no campo da educação, reinscreve à sua maneira a divergência que se instalou no seio mesmo da tradição freudiana, uma vez morto o pai da criatura, conforme assinalado por Roudinesco (1994). As correntes anglo-saxônicas acabaram enveredando por certo determinismo pragmático tanto na formação de analistas quanto na prática da psicanálise, ao tempo que deixavam de lado de formas diferentes a referência à obra e à doutrina freudiana. Já as correntes em cuja origem está em causa o ensino lacaniano, ora pelo fato de segui-lo de diferentes formas, ora por dele se distanciar cada uma a sua maneira, dão a ver uma grande diversidade na forma de declinar a prática analítica ao tempo que mantém cada um à sua maneira a referência às noções e aos conceitos forjados inauguralmente por Freud.

Assim sendo, "a abordagem clínica de orientação psicanalítica em ciências da educação" é tomada pela preocupação metodológica, pois desta dependeria a especificidade da abordagem, bem como a sua própria legitimidade perante a psicanálise como saber de referência, bem como perante as outras ciências da educação. Já no Brasil, a referência obrigada à obra freudiana, na esteira de uma obediência pluralista do mandato lacaniano de se retornar à Freud e à sua experiência inaugural, outorga certa legitimidade, bem como possibilita a singularidade na hora de fazer comparecer a psicanálise no campo da educação.

\section{A questão da questão da psicanálise}

Os educadores Pfister, Zulliger e Airchhorn, partidários junto a outros do movimento de renovação pedagógica iniciado à luz da psicanálise há um século e conhecido como pedagogia psicanalítica, valeram-se do termo "aplicação" para qualificar semelhante empreitada. Freud, em diferentes oportunidades, valeu-se expressamente do mesmo como, por exemplo, nos textos Introdução a The Psycho-analytic method de Pfister (1913), Dois verbetes de enciclopédia: Psicanálise (1923), Prefácio à Juventude Desorientada de Aichhorn (1925) A questão da psicanálise leiga (1926). Esclarecimentos, aplicações e observa- 
ções (1932). Já, em outras oportunidades, deixou de lado o termo "aplicação" e referiu-se à questão em termos do "interesse" que a psicanálise revestia para a pedagogia e educação nos textos $O$ interesse científico da psicanálise (1913) e Conferência Introdutória sobre a psicanálise, número 23 (1916-1917).

A renovação pedagógica perseguia a transformação das relações humanas no embalo da esperança pós-primeira grande guerra. Assim, a empresa de aplicação da psicanálise foi rapidamente tomada pelo espírito profilático, professado inclusive por Freud no início da sua obra. (LAJONQUIÈRE, 2009). Grande parte das iniciativas visava evitar o aparecimento da neurose. Entretanto, hoje em dia, não há ao menos no campo psicanalítico francês ou brasileiro nenhuma pretensão deliberada nesse mesmo sentido, a despeito das iniciativas que visam "intervir a tempo" (KUPFER, 2012) ou precocemente.

O termo aplicação - diferentemente do Brasil onde os desenvolvimentos do LEPSI sempre obraram nesse sentido - não foi posto de lado de forma explícita no campo pedagógico francês. Um texto de Nicole Mosconi ${ }^{9}$ publicado em 1986 na Revue Française de Pédagogie relança expressamente o debate em torno da pertinência de seu uso. Ele ajuda a pensar o tipo de referência que os franceses fazem à psicanálise quando se trata do que eles chamam "Abordagem clínica de orientação psicanalítica em ciências da educação".

Mosconi acredita na possibilidade de se construir de forma analógica à invenção freudiana uma verdadeira "ciência aplicada", que não se reduziria a uma simples somatória de prescrições pedagógicas. Ao contrário, os participantes dessa empresa seriam sujeitos que, tendo a experiência das tarefas formativas, bem como tendo sido em algum momento beneficiados pela realização de uma análise pessoal, exprimiriam ainda o desejo de saber mais sobre suas próprias práticas profissionais. Essa aplicação seria uma operação, ora capaz de propor regras práticas, a partir de um determinado saber científico, com vistas à realização de um objetivo definido previamente, ora produtora de uma ciência mais "complexa (no sentido cartesiano)" (MOSCONI, 1988, p. 74) resultante de ter se aplicado aquela "simples" a um "objeto novo". No primeiro sentido, o objetivo da aplicação da psicanálise seria claramente utilitário; já no segundo, não. Assim, a "psicanálise aplicada" poderia ser entendida nessa segunda acepção como, por exemplo, no caso da óptica geométrica (ou a cinemática aplicada) com relação à geometria (ou a cinemática) muito mais simples que aquela.

Na continuação, Mosconi assinala que quando Freud "aplicou" a psicanálise a diversas produções da cultura, ele não visava a nenhum objetivo prático. $\mathrm{O}$ interesse teria sido o de produzir um saber teórico. Então, neste ponto, nossa

9 Integrante, na época, da equipe da universidade Paris 10 que publicou na mesma revista os textos que fazem o balanço da produção na área temática. 
autora chama a atenção para a singularidade própria da elaboração psicanalítica, bem como em particular da experiência freudiana: a construção teórica implica a elucidação do "próprio psiquismo" do "pesquisador", nas palavras da autora. Por isso, nas suas conclusões, afirma ainda que os pesquisadores dessa nova "ciência aplicada" deveriam fazer uma "análise" pessoal dando mostras, assim, de um "verdadeiro desejo de saber sobre si mesmo e sua prática". (MOSCONI, 1988, p. 78).

No entanto, Mosconi logo reclama para esta ciência aplicada também uma dimensão técnica, da mesma forma que no interior do mesmo campo psicanalítico haveria uma "técnica da cura" que como "saber prático" faria a "intermediação" entre a pura metapsicologia e a singularidade do paciente. A elaboração dessas regras seria ainda incipiente, mas não se trataria - ao contrário do afirmado por outros, segundo ela - de uma impossibilidade radical inerente à "teorização inspirada na psicanálise e que tivesse por objeto as práticas pedagógicas". (MOSCONI, 1988, p. 74). Ela observa ainda a necessidade de que essa "teoria" considere aquilo que distinguiria as "práticas educativas" da "prática da cura". A seu ver isso seria o fato de a educação ser sempre uma prática de grupo à diferença do dispositivo da cura em princípio restringido ao par terapêutico. Mosconi assim conclui que em se considerando a sua fertilidade já demostrada, a clínica de grupos de inspiração psicanalítica seria uma peça-chave na constituição desse novo saber tanto teórico quanto prático da psicanálise aplicada à educação.

Pois bem, a aposta da colega é grande, bem como a sagacidade de seu raciocínio. Todavia, creio pessoalmente que, ainda assim, cabe pensarmos numa outra direção na esteira dos desenvolvimentos brasileiros atuais.

A diferença entre a prática pedagógica e aquela da cura não é de simples quantidade de participantes, conforme pensa Mosconi. A direção de cada uma delas é qualitativamente específica. Isso não deve ser duvidoso para os leitores que já sabem de minha insistência em frisar duas distinções: a primeira, entre a dita prática pedagógica e a simples educação como discurso ou laço social, seja familiar ou escolar (LAJONQUIÈRE, 1999), e, a outra, entre os dispositivos da cura (com adultos ou com crianças) e os de formação ou educação, mesmo aqueles situados além da pedagogia hegemônica. (LAJONQUIÈRE, 2009).

Nossa autora acaba apontando implicitamente para a dissociação da triplicidade da psicanálise: tratamento, investigação e metapsicologia. Isso seria factível uma vez que - na esteira dos desenvolvimentos da psicanálise inglesa - ela postula a elaboração, por dedução, de uma técnica da cura - a análise da transferência -, embora reconheça que a prática sempre é mais complexa e imprevisível que aquilo que estamos dispostos a aceitar. Essa "técnica da cura" dissociada da dimensão tríplice passa a inscrever no horizonte a possibilidade 
mesma que o inconsciente seja um saber reflexivo ${ }^{10}$. Para Mosconi, a "aplicação" da psicanálise à mesmíssima cura comportaria regras práticas susceptíveis de serem elaboradas a priori por dedução, bem como executadas sempre e quando o analista levar em conta sua própria participação contratransferencial. Situação análoga se daria - segundo nossa autora - na "ciência aplicada", na qual o pesquisador das práticas pedagógicas deveria levar em conta a "participação transferencial do pesquisador no objeto de pesquisa". (MOSCONI, 1988, p. 75).

Não obstante, como já dito, embora a psicanálise seja ternária, ela é uma só. É isso mesmo o que a saga freudiana coloca em ato, assim como, renova-se ainda hoje em toda experiência analítica. Tem-se dito que a psicanálise é ora uma ciência judia, ora uma ciência burguesa, bem como outras vezes nem sequer atingiria estatuto algum de ciência, pois seria a "doença" mesma de seu inventor. Porém ela é simplesmente o produto de uma experiência pessoal, qual seja a própria cura de Freud, desdobrada inclusive em ressonância com aquela de seus pacientes. Por isso, por exemplo, o complexo de Édipo não é descoberto nem nos pacientes, nem nele mesmo. O Édipo é elevado à categoria de peça metapsicológica no decorrer de uma experiência de simbolização d'isso ${ }^{11}$ mesmo que resta no interior do campo da palavra e da linguagem e do qual todo sujeito goza.

Freud poderia não ter escutado esse discurso Outro que é o inconsciente. Poderia ter reproduzido no encontro com seus pacientes a mesma surdez que prima no laço social cotidiano. Se assim tivesse feito, teria "descoberto" nos pacientes as mesmas "realidades" "descobertas" pelos seus detratores, efeitos do recalque cotidiano que ele mesmo, então, teria reproduzido em ato na investigação e na direção do tratamento. Mais ainda, poderia ter naturalizado a sua "descoberta" afirmando que verificou a existência daquilo que já estava de fato lá. Porém, por um lado, Freud nada descobre, pois nada há por baixo de coberta alguma. Ele simplesmente renuncia à inercial reprodução da estratégia hegemônica de silêncio e naturalização e, assim, passa a desconstruir a operação discursiva produtora de sintomas no interior da única realidade que conta para nós "humanos", aquela mesma do discurso, onde a experiência da palavra é possível. É nesse sentido que entendo a afirmação lacaniana de ser a psicanálise uma experiência do bem-dizer (LACAN, 1974), bem como que toda ideia de técnica da cura não pode menos que recair nas garras do utilitarismo, reprodutor da surdez pão-nosso discursivo de todos os dias.

O mesmo vale para a "ciência aplicada" proposta. Mosconi destaca a factibilidade da técnica da cura para depois entrever a elaboração de uma técnica

10 Lembre-se do destaque que tem na França a dita "relação com o saber".

$11 \mathrm{O}$ isso é um dos nomes lacanianos do inconsciente em português. 
- via reflexão capaz de destacar no horizonte do discurso teoria e prática - para uma nova prática pedagógica supostamente elucidada pela psicanálise. Vê-se, então, que é esse mesmo objetivo técnico que anima aquela ideia de nossa autora relativa à aplicação da psicanálise sobre "objetos novos", como, no caso, o ensino. Esses objetos seriam não-psicanalíticos, assim como as religiões, a produção científica e artística de Leonardo da Vinci, "A Gradiva" de Jensen, ou o delírio de Schreber seriam objetos situados "fora da cura" sobre os quais Freud teria aplicado a teoria em prol de compreendê-los. (MOSCONI, 1988, p. 74). Mosconi desconhece, pelo fato mesmo de ter desamarrado a triplicidade da psicanálise, que não há objetos situados fora do tratamento psicanalítico. A psicanálise decompõe esses objetos culturais, encontrando neles os mesmos elementos constituintes "encontrados" nas questões que trabalhavam "interiormente" os analisantes. Assim, toda vez que Freud "aplica" a psicanálise supostamente fora da cura, não faz mais do que fazer avançar a psicanálise e a cura - a sua própria e aquela que a psicanálise propõe.

Finalmente, não creio que o "ensino" ou o didatismo das práticas profissionais não possa ser um "objeto novo" de análise dessa nova ciência, nascida por aplicação, pelo fato de não ser supostamente um objeto fora da cura. A insistência de se destacar tanto o ensino quanto a possível teorização denuncia o reducionismo didaticista operante no campo pedagógico. Ao contrário, é por ele ter sido fabricado via redução que não pode ganhar o estatuto de objeto de estudo analítico. O seu tratamento analítico, na contramão, visa desconstruir a operação de redução que o fabricou como objeto suscetível de técnica de aperfeiçoamento pedagógico. Por outro lado, a educação seria também um objeto fora da cura? Mas, a educação não seria aquilo que os adultos de plantão estão incumbidos de fazer todos os dias com as crianças chegadas ao mundo, pela simples razão de há certo tempo eles mesmos terem se beneficiado de uma operação semelhante? Pois bem, é disso, de seus excessos e carências, de sua natureza faltante, que os analisantes tratam nas curas.

Chegado a esse ponto, creio que talvez seja mais simples que o imaginado por Mosconi responder ao desígnio freudiano de se aplicar a psicanálise à educação. Lembremos que se predica a "aplicação" de uma pessoa, isto é, dizemos de sua "dedicação meticulosa" na realização de uma tarefa determinada. Por exemplo, "Fulano é alguém muito dedicado à [...]" ou "Beltrano é alguém que se dedica à [...]". Por sinal, é nessa mesma direção que apontaria Freud quando se vale do termo "interesse" para dizer das implicações dos avanços psicanalíticos para outros campos do saber não terapêuticos (ou não médicos como ele dizia na época) dentre os quais a pedagogia. Em soma, a psicanálise "aplicada ou dedicada à educação" seria a mesma e única psicanálise de sempre que dessa forma em nada veria sacrificado o seu interesse ou potencialidade analítica inaugural. 
Psicanálise que na expansão constante de suas fronteiras, pelo simples fato de estar sempre viva - como qualquer reflexão fértil que não é nem um sonho de uma noite de verão, nem um golpe de marketing tecnocientificista -, passa a se dedicar a "objetos" não considerados pela hegemonia paradigmática até certo momento atrás como se tal coisa lhe dissesse respeito. Mais ainda, expansão das fronteiras desejada pelo pai de singular criatura - Sigmund Freud - que teria a particularidade de sujeitar no interior do movimento psicanalítico àqueles que se aventuram a operar com a sua criação.

Por essa mesma razão, todos os educadores que se interessaram pioneiramente pela dita aplicação acabaram por engrossar as fileiras do movimento psicanalítico a título de analistas profanos ou analistas-pedagogos pelo fato de não serem médicos nas primeiras décadas do século XX. Talvez seja por isso que, ainda hoje, e particularmente no Brasil, os que se interessam pela psicanálise e pela educação acabam se interessando simplesmente pela psicanálise sem muitas ressalvas, à diferença de não poucos franceses. Assim, eles acabam renunciando à pretensão de aplicar a psicanalise à educação e passam, ao contrário, a simplesmente se implicar subjetivamente na causa freudiana. Foi essa implicação que acabou afastando os pioneiros de antanho, como também afasta aqueles de hoje, do campo ortodoxo da pedagogia e de seu voto tecnocientificista, fazendo que contribuam com o desdobramento da mesmíssima psicanálise no tempo.

\section{REFERÊNCIAS}

BLANCHARD-LAVILLE, C.; CHAUSSECOURTE, P.; HATCHUEL, F.; PECHBERTY, Bernard. Recherches cliniques d'orientation psychanalytique dans le champ de l'éducation et de la formation. Revue Française de Pédagogie, n. 151, p. 111-162, 2005.

BLEGER, J. Temas de psicologia. Buenos Aires: Nueva Visión, 1964.

FILLOUX, J.-C. Psychanalyse et pédagogie: ou d'une prise en compte de l'inconscient dans le champs pedagogique. Revue Française de Pédagogie, n. 81, p. 69-102, 1987.

FREUD, S. O mal-estar na civilização. In: FREUD, S. Obras Psicológicas Completas. Rio de Janeiro: Imago, 1980 [1930]. v. XXI. p. 81-178. FREUD, S. Introdução a The Psycho-analytic method de Pfister. In: FREUD, S. Obras Psicológicas Completas. Rio de Janeiro: Imago, 1980 [1913]. v. XII. p. 415-422.

FREUD, S. O interesse científico da psicanálise. In: FREUD, S. Obras Psicológicas Completas. Rio de Janeiro: Imago, 1980 [1913]. v. XIII. p. 199-229. 
FREUD, S. Vias de formação de sintomas - Conferência Introdutória sobre a psicanálise, número 23. In: FREUD, S. Obras Psicológicas Completas. Rio de Janeiro: Imago, 1980 [1916-1917]. v. XVI. p. 320-334.

FREUD, S. Dois verbetes de enciclopédia: Psicanálise. In: FREUD, S. Obras Psicológicas Completas. Rio de Janeiro: Imago, 1980 [1923]. v. XVIII. p. 287-307.

FREUD, S. Prefácio a Juventude Desorientada de Aichhorn. In: FREUD, S. Obras Psicológicas Completas. Rio de Janeiro: Imago, 1980 (1925). v. XIX. p. 341-348.

FREUD, S. A questão da psicanálise leiga. In: FREUD, S. Obras Psicológicas Completas. Rio de Janeiro: Imago, 1980 [1926]. v. XX. p. 211-284.

FREUD, S. Esclarecimentos, aplicações e observações - Novas conferências introdutórias sobre psicanálise, número 34. In: FREUD, S. Obras Psicológicas Completas. Rio de Janeiro: Imago, 1980 [1932]. v. XXII. p. 118-225.

KUPFER, M. C. et. al. A produção brasileira no campo das articulações entre psicanálise e educação a partir de 1980. Estilos da Clínica, v. 15, n. 2, p. 284-305, 2010.

KUPFER, M. C. (Org.). Psicanálise e ações de prevenção na primeira infância. São Paulo: Escuta, 2012.

LACAN, J. Televisão. Rio de Janeiro: Jorge Zahar Editor, 1993 [1974].

LAJONQUIÈRE, L. de. Infância e ilusão (psico)pedagógica. Petrópolis: Vozes, 1999.

LAJONQUIÈRE, L. de. Figuras do infantil. Petrópolis: Vozes, 2009.

MOSCONI, N. De l'application de la psychanalyse à l'éducation. Revue Française de Pédagogie, n. 75, p. 73-79, 1988.

MOKREJS, E. A Psicanálise no Brasil. Petrópolis: Vozes, 1992.

PEREIRA, M.; SILVEIRA, W. Análise do estado da arte em psicanálise e educação (1987-2012). Estilos da Clínica, v. 20, n. 3, p. 369-390, 2015.

ROUDINESCO, E. Genealogias. Rio de Janeiro: Relume Dumará, 1995 [1994].

Texto recebido em 17 de dezembro de 2016. Texto aprovado em 03 de janeiro de 2017. 
